\title{
LOS USOS DE “TÚ” Y “UD.” EN LOS ACTOS DE HABLA: UNA APROXIMACIÓN A LA PRAGMÁTICA DEL BILINGÜE
}

The Uses of "tú" and "Ud." in Speech Acts: An Approximation to the Bilingual's Pragmatics

Carolina Gutiérrez-Rivas*

Resumen

La presente investigación versa sobre el uso de los pronombres de tratamiento "tú" y "Ud." en la formulación de peticiones, por parte de bilingües cubanoamericanos, de segunda y tercera generación, residenciados en el área de Miami, Florida. Un análisis cualitativo determinó que el uso explícito de los pronombres dentro del acto de habla cumple con una doble función pragmática: 1) la de ensalzar al oyente y expresarle empatía y 2) la de marcar distanciamiento con el interlocutor.

Palabras clave: Cortesía, pronombres de tratamiento bilingües cubanoamericanos.

Abstract

This paper explores how second and third generation Cuban Americans from Miami, Florida, use the address pronouns "tú" and "Ud." when formulating speech acts such as requests in Spanish. A qualitative analysis shows that the explicit use of the pronouns when uttering a speech act fulfills a double purpose: 1) to flatter the hearer and express solidarity towards her/him, and 2) to establish distance towards the interlocutor when the speaker is in a position of power.

Key words: Politeness, address pronouns bilingual Cuban Americans.

\section{INTRODUCCIÓN}

Nuestro objetivo es describir la variación, alternancia y funciones pragmáticas de los pronombres de tratamiento "tú" y "Ud." en actos de habla tal como ocurren en las peticiones por parte de bilingües cubanoamericanos. A través del análisis cualitativo de los datos, se mostrará que, en referencia a los actos de habla, los bilingües del área de Miami insertan uno u otro pronombre de tratamiento en la petición como estrategia para mostrarse solidarios o distantes en situaciones muy específicas, y que su uso de los pronombres se diferencia, en ciertos aspectos, de la norma monolingüe (tal como ha sido descrita en varias regiones del mundo hispánico) así como, también, converge en otros. Se verá que la dicotomía deferencia/solidaridad, expresada a través de los pronombres de cortesía, adquiere patrones particulares dentro de esta comunidad de

\footnotetext{
${ }^{1}$ Se parte aquí de la definición dada por Searle sobre los actos de habla: "las unidades básicas o mínimas de la comunicación lingüística" (1975:16, mi traducción). Explica Searle que la unidad lingüística de la comunicación no es meramente el símbolo, la palabra o la oración, sino la producción de todos ellos combinados en la emisión de un acto de habla, que puede tener forma de afirmación o pregunta y usarse para dar direcciones, pedir cosas, dar las gracias, etc.
} 
habla ${ }^{2}$ (por ejemplo, la alternancia de uno u otro pronombre dentro de un mismo acto de habla para proyectarse, más o menos, distante ante un oyente determinado). Se infiere que tales patrones de uso (que se verán expresados a lo largo del trabajo), podrían deberse, entre otros factores, a un cambio en marcha, no sólo del español hablado en los Estados Unidos, sino del mundo. Además, se revelará la diferencia que existe entre la autopercepción del bilingüe sobre su propia (in)formalidad a través del uso de estos pronombres y la producción que hacen de éstos en la realidad.

Asimismo, esta investigación ofrece una perspectiva nueva sobre el tema, al describir el comportamiento de una comunidad de habla cuyo uso (alternado) de los pronombres dentro de los actos de habla responde a variables distintas de las que influyen el habla monolingüe. Dichas variables están determinadas en gran medida por el nivel de competencia linguística y la frecuencia de socialización de los bilingües en la segunda lengua, es decir, el español.

\section{REVISIÓN DE LA LITERATURA}

Estudios históricos sobre el uso de los pronombres de tratamiento revelan que en latín el "tú" se usaba, al igual que en la actualidad, como una forma de tratamiento singular informal, que no ha variado con el tiempo (Cfr. Penny, 2002). El "Ud.", por el contrario, evolucionó de "vuestra merced": “(...) en el siglo XV, la forma de cortesía deferencial deriva en vuestra merced, con un verbo en tercera persona del singular, vuessa merced y, en el siglo XVII, usted' (Uber, 1985:388. Mi traducción).

Brown y Gilman afirman que, así como en español, en francés e italiano siguen activos dos pronombres de tratamiento singulares que derivaron del latín "TŪ" y "VŌS". Partiendo de la base de que las relaciones humanas son asimétricas, es decir, se basan en una jerarquía que se refleja en la lengua, Brown y Gilman argumentan que ambos pronombres están estrechamente relacionados con los conceptos de poder y solidaridad. Los autores denominan a este proceso "semántica del poder" y afirman que es esta dinámica la que va a determinar el uso de los pronombres "tú" y "Ud." en la conversación: “(...) la semántica del poder sólo prescribe el uso entre superior e inferior y propone una estructura social en la que cada individuo se ubica en un rango único de poder" (1997:256. Mi traducción). En toda comunidad de habla donde exista el uso de más de un pronombre de tratamiento, la semántica del poder funciona de modos diferentes. Por ello, la alternancia de las formas pronominales está estrechamente relacionada con la intención del hablante de mostrar deferencia o solidaridad ante su interlocutor, en algunos casos, independientemente de variables externas, como la edad y la distancia social con el interlocutor. En el presente estudio se pone de manifiesto que la asociación rígida de

\footnotetext{
${ }^{2}$ Usamos el concepto de comunidad de habla tal como lo definen Gumperz y Hymes: "Una comunidad que comparte reglas de la conducta e interpretación del discurso y reglas para la interpretación de, al menos, una variedad lingüística" (1972:54. Mi traducción).
} 
un pronombre u otro con la deferencia ("Ud.") o la solidaridad ("tú") resulta errónea al aplicarla a ciertas comunidades lingüísticas.

En algunas variedades monolingües del español de América se observan variaciones respecto a la alternancia de los tres pronombres disponibles en esta lengua, a saber "tú", "Ud." y "vos". Por ejemplo, en su investigación sobre las formas de tratamiento en Bogotá (Colombia), Uber asegura que existen dos tipos de Ud. en esa región: el "Ud." de no solidaridad se usa generalmente con desconocidos (policías, meseros, etc.) y el de solidaridad se usa con personas cercanas (miembros de la familia, etc.). El "tú", por su parte, ocupa un lugar intermedio: "puede utilizarse para denotar cierta familiaridad o confianza, pero aún así implica cierta distancia" (1985:389. Mi traducción). Las observaciones de Uber la llevaron a concluir que el "tú", a pesar de no ser la forma de más solidaridad, es la que se está expandiendo más hacia ambos extremos del continuo, y que el uso del pronombre deferencial será menos frecuente en el futuro. Igualmente, en otro estudio sobre el habla de Colombia, Murillo encontró que en el área de Popayán el uso del pronombre "vos" predomina sobre el del tuteo y el ustedeo.

En Costa Rica, Hasbún y Solís hallaron una gran asimetría en las formas de trato, ya que "en Costa Rica, pareciera existir un uso dual del 'usted': uno que refleja formalidad y respeto y otro que implica una mayor intimidad y que es determinado por la situación" (1997:145). Igualmente, Rey analizó el uso del "vos" y el "Ud." en Managua, Nicaragua, y encontró que el voseo cumple diferentes funciones en esta comunidad: solidaridad, intimidad y familiaridad "superficial" (1996:113).

En Cuba, Lipski observó que el ustedeo no es un rasgo lingüístico predominante, tal como lo es en otras culturas hispánicas como la costarricense, la hondureña, la mexicana o la colombiana. Lipski nota que: "el español de Cuba emplea de modo uniforme tú como pronombre familiar. En el uso actual, este tratamiento se extiende a las personas que se acaba de conocer en circunstancias donde el usted sería más común en otros dialectos del español" (1996:258). Por su parte, lo encontrado en los datos de esta investigación sugiere que los bilingües se están apartando de la norma para hacer uso de los pronombres de una manera que se adapte más a las necesidades de su contexto comunicativo y a la vez sea perfectamente aceptable dentro de su propia comunidad de habla.

Existe además, en el español moderno, un fenómeno lingüístico conocido como "polimorfismo" que consiste en utilizar "varias formas de tratamiento con un mismo interlocutor y en un mismo acto comunicativo, con una intención comunicativa determinada" (Murillo, 2003:11). En su estudio, Murillo se refiere a la mezcla y uso explícito de los tres pronombres de tratamiento disponibles en el habla colombiana, a saber, "tú", "vos", y "Ud.". Es así como se considerará el concepto de polimorfismo en el presente estudio, aunque incluyendo sólo los pronombres "tú" y "Ud.", ya que este fenómeno se asemeja en muchos aspectos a lo observado en la comunidad de habla de cubanoamericanos de segunda y tercera 
generación de la ciudad de Miami, punto sobre el cual se volverá más adelante. No se consideran como polimorfismo los casos en que se alteran los pronombres con las formas verbales de segunda o tercera persona, puesto que tales casos no fueron considerados ni incluidos en la noción de polimorfismo ofrecida por Murillo.

En lo referente a la cortesía y el estudio de sus pronombres se entiende que su uso está estrechamente relacionado con el trato y el tipo de relación entre hablante y oyente, así como con las intenciones del uno para con el otro en el marco comunicativo. En las lenguas en las que se cuenta con dobletes pronominales (o en el caso de algunos dialectos del español, tripletes) se produce una especie de proceso de retroalimentación en el que, en un contexto dado, el estatus de ambos interlocutores influenciará al hablante en la elección de un pronombre sobre otro; pero a la vez, el uso del pronombre elegido fungirá como marcador de distancia social entre ambos. De igual modo, las formas pronominales de trato se usan para moldear la propia imagen, o la que se pretende tener, ante el interlocutor de turno. Brown y Levinson postularon que, durante el curso de la interacción comunicativa, los hablantes que necesiten la aprobación de su interlocutor intentarán salvaguardar su imagen positiva o usar las fórmulas de solidaridad, y los hablantes que deseen lograr el respeto del oyente se dedicarán a salvaguardar su imagen negativa con el uso de fórmulas deferenciales. ${ }^{3}$ Respecto a las formas de tratamiento, los autores, refiriéndose a lenguas como el francés, arguyen que la cortesía es el principal motivador para el uso de ciertas formas pronominales.

En español también se han llevado a cabo algunos estudios respecto a la variación de los pronombres en correlación con variables como solidaridad y poder (Cfr. Ardila, 2005; Blas-Arrollo, 2005; Lavandera, 1984; Turell, 1989; Stewart, 2003; etc.). Sin embargo, al parecer aún no existen estudios que determinen qué uso dan a los pronombres de tratamiento las comunidades bilingües de español e inglés de los Estados Unidos (en especial, la escogida para esta investigación).

\section{LA METODOLOGÍA Y LOS PARTICIPANTES}

La muestra de la presente investigación proviene de veinte hablantes que se escogieron intencionadamente tomando en cuenta factores como la edad, el lugar de nacimiento y el lugar de residencia actual. La labor de reclutamiento de los participantes y las entrevistas se llevaron a cabo en la ciudad de Miami, Florida. Luego de contestar un cuestionario con su información personal (con datos como los

\footnotetext{
${ }^{3}$ Según Brown y Levinson (1987) las estrategias de cortesía positiva son las usadas para satisfacer los deseos de aprobación del oyente y las estrategias de cortesía negativa son las que se usan para satisfacer la necesidad de respeto al espacio propio del oyente. Además mencionan otros tres tipos de estrategias que no fueron observadas en los datos. Por su parte, Scollon y Scollon (1983) establecen que las estrategias de Brown y Levinson pueden denominarse estrategias de solidaridad para referirse a la cortesía positiva, y estrategias de deferencia para referirse a la cortesía negativa. Usaremos ambas terminologías indistintamente.
} 
enumerados en las líneas anteriores), los participantes hicieron dramatizaciones de situaciones específicas (role-playing), las cuales fueron grabadas en audio. Posteriormente, realizaron una prueba de autoevaluación oral sobre su percepción del uso de los pronombres "tú" y "Ud.". Las situaciones a dramatizar fueron diseñadas siguiendo los parámetros (Intercultural Comunication) propuestos por Scollon y Scollon (2001), quienes afirman que existen tres sistemas de cortesía aplicados a las normas pragmáticas: jerarquía, deferencia y solidaridad. Estos tres sistemas pueden observarse en variados contextos y se basan principalmente en las diferencias de más o menos poder $\left(+\mathrm{P}\right.$ o-P) y más o menos distancia $(+\mathrm{D}$ o $-\mathrm{D})$ entre los participantes. ${ }^{4}$ En este trabajo se toma en cuenta el concepto de bilingüe tal como lo define Silva-Corvalán, quien considera bilingüe a todo individuo que

(...) tiene un cierto grado de competencia en el uso de dos lenguas como vehículos de comunicación, sin que este grado de competencia tenga necesariamente que ser igual al que posee un hablante de la variedad estándar de las lenguas en cuestión (2001:270).

Como se mencionó, los veinte hablantes bilingües de segunda y tercera generación se seleccionaron tomando en cuenta el lugar de nacimiento (Cuba o Estados Unidos) y la edad en que llegaron a los Estados Unidos en covariación con la edad cronológica. El primer grupo, constituido por hablantes de segunda generación, estuvo comprendido por cinco mujeres (RR2, MJ2, MR2, GB2, LK2) y cinco hombres (LJ2, JG2, AP2, EL2, RS2) entre 40 y 53 años de edad. En este grupo se incluyeron a aquellos bilingües que nacieron en Cuba pero llegaron a Miami antes de la edad de 12 años, o que nacieron en los Estados Unidos de padres cubanos. El segundo grupo, constituido también por diez hablantes, cinco mujeres (EL3, DZ3, KS3, LM3, LP3) y cinco hombres (DR3, AR3, DP3, GD3, AC3), se conformó de personas nacidas en Miami, quienes tienen al menos un padre o una madre de segunda generación. En este grupo se incluyó a personas entre los 18 y los 28 años de edad. Cabe destacar que, a pesar de que todos estudiaron español en algún momento de la escuela primaria, secundaria y/o superior, ninguno de ellos asistió a escuelas bilingües. Los números 2 y 3, añadidos a los códigos de identificación de los participantes, indican si son de la segunda o la tercera generación respectivamente. Como ya se acotó, en el presente estudio el uso del término "generación" se correlaciona directamente con edad y, posteriormente, se verá cómo la variable

\footnotetext{
${ }^{4}$ Situaciones planteadas a los participantes para la dramatización:

Situación 1. Sistema de cortesía deferencial (-Poder, +Distancia): Debe hacer que su vecina/o lo lleve al aeropuerto.

Situación 2. Sistema de cortesía de solidaridad (-Poder, -Distancia): Debe hacer que su comadre/compadre o mejor amiga/o le preste dinero.

Situación 3. Sistema de cortesía según la jerarquía (+Poder,+/-Distancia): Debe hacer que su empleada/o se ponga a trabajar en un proyecto que está pendiente.
} 
externa de la edad es un factor influyente en la elección de una forma pronominal sobre otra, fenómeno que ya ha sido observado también en otras regiones de habla hispana (Cfr. Blas-Arroyo, 1994).

Dado que la meta de esta investigación era determinar el uso de las estrategias pragmáticas de los bilingües teniendo en cuenta variables sociales como jerarquía, deferencia y solidaridad, se usaron principalmente dos de los métodos más aceptados en la recolección de enunciados que contienen actos de habla, a saber, la dramatización de situaciones específicas y el protocolo de autoevaluación oral. Es preciso aclarar que los participantes realizaron la dramatización pensando en un oyente imaginario, ya que el propósito del trabajo se limitó sólo al análisis del pedido y no a las respuestas. Se prefirió usar el método oral frente al escrito (o el Discourse Completion Test usado por BlumKulka; House y Kasper; Curcó; Curcó y De Fina; Félix-Brasdefer, entre otros), puesto que se pensó que los hablantes tendrían menos tiempo de monitorear su propio discurso y hablarían, por ello, de manera más espontánea.

Por su parte, el protocolo de autoevaluación oral es una técnica que ayuda a sustentar la investigación pragmática al examinar el proceso de pensamiento que siguen los hablantes al producir los diálogos, y consiste en pedir al participante su propia opinión acerca de los enunciados que ha producido. Con esta prueba se tiene una mejor idea de lo que piensan los hablantes acerca de las estrategias y técnicas que utilizan para hacer pedidos, y de si se perciben a sí mismos como individuos (in)formales a través del habla.

\section{RESULTADOS Y DISCUSIÓN}

Blum-Kulka, House y Kasper sostienen que el grado de distancia social y poder entre los hablantes determina en gran medida la variación de los actos de habla. Ardila (variables sociopragmáticas) señala que en buena parte de la bibliografía sobre las formas pronominales se afirma que los hablantes suelen emplear el tratamiento formal para personas de rango superior o igual cuando existe una relación distante, mientras que el tratamiento familiar lo aplican a los interlocutores de rango social igual o inferior. Sin embargo, al observar la producción de los pronombres de tratamiento por parte de los bilingües cubanoamericanos de Miami, se hizo evidente que la teoría que se sustenta en el habla monolingüe pierde su carácter estricto cuando se aplica al habla de los bilingües.

A continuación se detallan algunos casos en que los hablantes bilingües alternaron los pronombres "Ud." y "tú" con las formas verbales de la segunda persona, en las distintas situaciones en que se encontraban en una relación vertical respecto al oyente; es decir, cuando entraban en juego las variables 1) más distancia, menos poder; y 2) más poder en referencia al oyente. En los casos en los que tenían igual distancia e igual poder que el interlocutor, el uso explícito de los pronombres fue más uniforme, con una tendencia (aunque no exclusiva) a usar el pronombre informal 
"tú", o a hacer omisión de este pronombre y a usar las formas de segunda persona. Se debe destacar, antes de entrar de lleno en la reflexión, que los pronombres que se consideraron para el análisis son los que se encuentran cercanos al núcleo del acto de habla, es decir, de la pregunta con que se formula el pedido propiamente dicho. Las formas de tratamiento periféricas al núcleo del acto de habla se consideraron como parte de los movimientos de apoyo a la petición misma.

\section{DRAMATIZACIÓN DE LA SITUACIÓN 1: MÁS DISTANCIA/ MENOS PODER}

En este apartado se muestran los enunciados obtenidos de los participantes de segunda generación en la situación 1 (+distancia/-poder). En esta situación los hablantes debían pedir a su interlocutor, en este caso una vecina o vecino con el que tuvieran poco trato, que los llevara al aeropuerto. Dada su posición de desventaja, se observa cómo LK2 recurre al uso del pronombre "Ud." para enfatizar respeto hacia el oyente, a la vez que lo intercambia con marcadores del discurso en segunda persona (ej.: "mira"). MR2 omite el uso del pronombre al formular el pedido la primera vez, y aunque usa una forma verbal en segunda persona, hace un intento por mostrarse formal al usar el posesivo en tercera persona (ej.: "su carro"), y acaba por hacer explícito el pronombre formal al replantear la idea. MR2 muestra consideración e intenta reducir el peso de la imposición al sugerir que sea el interlocutor quien decida si puede prestarle el auto o llevarla al aeropuerto

(1) LK2: Carlos, mira, tengo esta situación que se me ha presentado, que el carro no me está encendiendo y, me gustaría que Ud. me hiciera el gran favor de llevarme hasta el aeropuerto, que tengo que recoger a alguien.

(2) MR2: Carlos, por favor, tengo una emengencia [sic], el carro mío no me, no me prende. Por favor, ¿me puedes hacer el favor de... prestarme su carro? $\mathrm{O}$ Ud. mismo me puede llevar al aeropuerto, porque de urgencia tengo que ir a buscar mis amistades, familia, que llegan de un viaje.

En el ejemplo (3), más adelante, se observa un caso similar a los primeros dos, ya que RR2 refuerza su pedido con la repetición del pronombre formal para mostrar deferencia hacia su interlocutor y, posteriormente, vuelve a hacerle el pedido usando el pronombre informal "tú". RR2 produce lo que en el habla monolingüe se consideraría "polimorfismo", o uso explícito de varios pronombres con un mismo sujeto, con el propósito de mostrar respeto al plantear el caso y empatía al hacer el pedido. En el ejemplo (4), EL2 alterna entre fórmulas de respeto formales e informales, como "disculpe" y "perdóname", atenuadores que le sirven para moderar el grado de imposición, pero se decide finalmente por el pronombre de solidaridad "tú" para hacer el pedido. En ambos casos, los pronombres se usan como estrategia positiva $^{5}$ para mitigar el impacto a la imagen

${ }^{5}$ Dice Johnstone (2005) que algunas maneras de expresar mitigación en la cortesía positiva son proclamar un terreno común, usar marcadores de identificación con el grupo, expresar aprobación o 


\section{Carolina Gutiérrez-Rivas}

(3) RR2: Mire, Carlos, ¿Ud. cree que Ud. me pudiera hacer el favor de recoger cierta persona? Me urge recogerla. La persona no tiene cómo llegar aquí, y entonces no tengo carro, mi esposo no me puede llevar, no tengo nadie que me pueda llevar, ¿tú crees que me pudieras recoger, me pudieras llevar a recoger el carro?

(4) EL2: María, disculpe y perdóname, pero tengo una emergencia, y por favor, no se sienta mal si no puedas, pero si puede, me harías un gran favor. Necesito ir al aeropuerto en este momento, aquí en el aeropuerto de Miami. Tengo unos familiares que me están llegando y el carro no me está funcionando en este momento. ¿Tú me harías el favor de dejarme, por lo menos, y después yo me ocupo de traer, de venir en un taxi?

Al pasar a la tercera generación, sin embargo, se constató en ocasiones la omisión de los pronombres, como en el ejemplo (5), página siguiente, a pesar de que las formas verbales y los títulos de tratamiento (ej.: "señora") se correspondían con la tercera persona. La escasa competencia en español de DZ3 ${ }^{6}$ la llevó a compensar la falta del pronombre con otras estrategias, como las explicaciones ("tengo unos familiares que me van a estar esperando...", "mi automóvil no enciende", etc.), los atenuadores ("perdón", "me da mucha pena", "por favor") y el compromiso de hacer un último esfuerzo por poner a funcionar su propio auto, todas éstas, estrategias de cortesía negativa. Ervin-Tripp (1972) menciona que, en lenguas con más de un pronombre de tratamiento, es necesaria una exposición intensa y prolongada a la lengua para conocer bien las reglas de alternancia por las que se rigen los dobletes pronominales, si es que se quiere lograr total competencia comunicativa en este aspecto. La autora menciona que existen casos en los que los individuos bilingües pueden emplear el cambio de códigos para evitar el uso de las formas de tratamiento. Sin embargo, a pesar de la poca exposición a la norma, la hablante logró su objetivo de mostrarse formal ante el oyente usando el español

compasión y complacer los deseos, intereses y necesidades del oyente. Las estrategias de mitigación de la cortesía negativa son evitar hacer presuposiciones sobre el interlocutor, demostrar deseo de no imponer nada al oyente, ser indirecto, disculparse, minimizar la imposición y hacer preguntas en vez de afirmaciones.

${ }^{6}$ Con los hablantes de todas las generaciones se mantuvo una conversación informal después de realizar las dramatizaciones con el propósito de estimular la producción de léxico y observar el uso de la concordancia a todos los niveles, además del manejo de las formas verbales. Las faltas de concordancia gramatical, densidad léxica y capacidad de elaborar oraciones complejas en español hicieron concluir que de todas las participantes de la tercera generación, DZ3 era la que menor nivel de suficiencia tiene en español. Para medir el nivel de suficiencia se siguió lo hecho en investigaciones anteriores, como la de Said-Mohand (2006): observar y tener en cuenta los errores o violaciones a los tres aspectos mencionados anteriormente, considerando que "error" es todo aquello que difiera del español normativo. Estudiosos como Zentella (1997) y Lynch (1998) afirman que un debilitamiento en el sistema verbal refleja, también, una disminución en la capacidad de uso de otros aspectos del habla (entre ellos, el lexical y el morfosintáctico). 
(5) DZ3: Mira, señora, perdón, me da mucha pena, pero tengo unos familiares que me van a estar esperando en el aeropuerto y mi carro no enciende. Primero voy a chequear si mi carro tiene algo con la batería o algo pa' arreglarlo. Por favor, si tiene un chance para llevarme al aeropuerto.

En general se observó que los hablantes de tercera generación prefirieron el uso del "tú", para dirigirse a un oyente con quien estaban en disparidad de poder y con quien tenían más distancia, como se observa en los ejemplos (6) y (7). La excepción se encuentra en el enunciado (8) en el que la hablante sí demostró manejo de la forma deferencial como en el habla estándar

(6) AC3: María, yo tengo unos familiares que vienen a visitarme por primera vez y me hace falta que... me hace falta llegar al aeropuerto, pero el carro no me arranca. Entonces, si tú me haces ese favor, te lo agradecería.

(7) DP3: María, yo tiene un problema, mi familia viene, ellos están en el aeropuerto, mi carro no está funcionando, si, por favor, me puede dar... hacerme un favor y me lleva al aeropuerto a coger mi familia. Y tú tienes un carro que está, tú sabes, tiene suficiente espacio pa' mi familia. ¿Tú me puedes llevar?

(8) LP3: Ay, Carlos, es que tengo que ir al aeropuerto y, ah, el carro no me enciende, si Ud. puede llevarme o, quizá si me puede prestar el carro se lo traigo pa' atrás.

\section{DRAMATIZACIÓN DE LA SITUACIÓN 2: MÁS PODER/ MÁS O MENOS DISTANCIA}

En la situación 2, (+ poder/+/-distancia), los hablantes debían pedir a su interlocutor, en este caso un empleado bajo su tutela, que acelerara el proyecto en el que se encontraban ambos trabajando. Cabe acotar que, según Scollon y Scollon (2001), cuando los hablantes tienen más poder que el oyente, la distancia entre ambos no juega un papel importante.

Se observó en la segunda generación que el uso del pronombre "Ud." sirvió para enfatizar la posición de poder del hablante y coaccionar al oyente, como se ve en el ejemplo (9). Igual es el caso del ejemplo (10), donde si bien el pronombre no aparece implícito en la petición, su uso dentro del enunciado es estratégico y cumple con la función de ratificar la jerarquía del hablante frente al oyente

(9) JG2: Carmen, lo siento mucho, pero Ud. tiene inmediatamente que empezar a hacer este trabajo y terminármelo, no hay opciones. Tiene que estar terminado y hay que terminarlo y si no, no se puede ir para la casa. $Y$ si se va, tan amigos.

(10) LJ2: Eh, mire, Carmen, estamos en, en una situación que el proyecto se tiene que terminar y veo que... $U d$. está un poquito atrasada. ¿La pudiera ayudar para terminar o, o puede conseguir a alguien que la ayudara a terminar el proyecto? 


\section{Carolina Gutiérrez-Rivas}

En el ejemplo (11), abajo, la hablante comienza su enunciado siendo informal y emplea primero el pronombre "tú", pero como se verá, inserta el pronombre formal en los momentos en que desea acortar la distancia con su interlocutor y mostrarle que se identifica con sus problemas. Como se observará, la repetición continua del pronombre "Ud." a lo largo del enunciado sirvió de objetivo doble a la hablante: el de reforzar su posición de autoridad ante el oyente, y a la vez hacerle entender que existe un lazo de empatía entre ambos

(11) LK2: Héctor, ¿cómo estás? Mira, Héctor, tú sabes que este proyecto es algo importante, y yo estoy de verdad lo más embullada de poder trabajar con Ud. Yo sé que Ud. tiene buenas intenciones, yo sé cómo es la vida en Miami, que todo el mundo está extremadamente ocupado, pero mire, le voy a decir la verdad, me estoy preocupando un poco, porque todavía no, no ha podido presentar los materiales y de verdad que ahora me urge que Ud. por favor, eh, eh... me traiga los materiales, porque ya la fecha se aproxima, y quiero saber de qué forma yo puedo facilitarle para que Ud. me traiga lo que me hace falta, porque así podemos seguir adelante con el proyecto.

Es preciso resaltar en este punto que, tal como refleja el ejemplo (11), algunos de estos bilingües están haciendo un uso de los pronombres de tratamiento que no concuerda con lo afirmado por Ardila (2003) para quien el pronombre "Ud." está reservado a personas de rango superior o igual. Es decir, que en el español normativo, se esperaría encontrar el uso de "tú" frente a un subalterno o alguien de rango igual o inferior. En este ejemplo en particular, el uso de los pronombres tampoco se compagina con lo documentado por Lipski (1996) quien afirma que el tuteo ocupa el lugar del ustedeo en circunstancias de tipo formal en el español monolingüe de Cuba. Contrariamente, en este caso, el uso del pronombre formal se asemeja a lo documentado por autoras como Uber (1985) y Hasbún y Solís (1997), quienes describen un uso dual del pronombre "Ud." con el propósito de reflejar formalidad con ciertos oyentes, e identificación y solidaridad con otros.

Por su parte, los hablantes de tercera generación mostraron preferencia por el pronombre de solidaridad "tú". Si bien hubo un intento por parte de DZ3, en (12), de mostrarse formal con el interlocutor al emplear el pronombre "Ud." en función de vocativo, optó por realizar su pedido usando el pronombre "tú"

(12) DZ3: Mira, Ud., esto es muy importante y necesito que tú me hagas esto.

En el ejemplo (13), el hablante emplea el pronombre informal y hace una repetición enfática del pedido a la vez que ejerce coacción sobre la oyente e impone su jerarquía o superioridad ante ésta. En el ejemplo (14) se incluye el enunciado de otro participante que también elige formular su pedido con el pronombre "tú". En ambos casos, el "tú" funciona como un intensificador, estrategia usada cuando el riesgo a perder la imagen es muy bajo. Cabe 
destacar que, probablemente, el uso de los pronombres en estos dos ejemplos sean los que más se asemejen a la norma monolingüe del español de Cuba

(13) DR3: Carmen, tú tienes que trabajar un poquito más porque este proyecto es muy importante para mí y para la comunidad y, estoy un poquito bravo ahora, porque tú no estás trabajando nada. Si tú puedes ayudarme un poquito... I'd appreciate it... Lo voy a apreciar muchísimo. Y si no, yo tengo que encontrar a alguien que pueda hacer el trabajo, porque ahora tú estás un poquito preocupada y desorganizada.

(14) EL3: Carmen, ¿tú puedes darme el proyecto? Lo necesito ahora.

\section{DRAMATIZACIÓN DE LA SITUACIÓN 3: MENOS DISTANCIA/MENOS PODER}

En la situación 3, los hablantes no se encontraban en una posición de desventaja ni de distancia con su interlocutor. En este caso, debían pedir a su comadre, compadre o mejor amiga o amigo que les prestara un dinero hasta finales del mes. Las relaciones no verticales parecieron promover, entre los hablantes de segunda generación, tanto el uso explícito del pronombre personal "tú" (ejemplo (15)), como de las formas verbales de la segunda persona y/o la omisión del pronombre (ejemplos (16) y (17)). De igual manera, tal como se observa a continuación, en ninguno de los tres casos se dio la alternancia de formas gramaticales de la tercera persona con las de segunda, como sí se vio en las situaciones en las que los hablantes presentaban más distancia y menos poder que el oyente. Nótese que, aparte del uso del pronombre de solidaridad y de las formas de segunda persona, los hablantes también crearon nexos de empatía con el interlocutor a través de las explicaciones, justificaciones y atenuantes (como "por favor", etc.), con los que buscaban moderar la imposición del pedido

(15) LK2: Ay, María, mira, mira lo que me ha pasado. Tú sabes que yo soy maestra y yo no trabajo en el verano y estamos un poco cortos, eh, eh... con respecto a la situación económica en este momento y me da mucha pena, pero me has, tú te has brindado en el pasado a ayudarme si se me presenta alguna situación económica difícil, y ahora se me ha presentado, y yo empiezo a cobrar en septiembre. Yo te agradecería mucho porque tengo un pago ahora que tengo que pendiente, que tengo que pagar y no tengo el dinero en este momento, si tú me harías el gran favor de, eh, de prestarme el dinero hasta que yo comience a trabajar. Tú sabes que yo soy buena paga.

(16) RR2: Mira, tengo este problema donde tengo que pagar esta cuenta, eh, hoy es el último día que lo puedo pagar, no tengo dinero, a lo mejor cobro el viernes y el viernes te doy el dinero para atrás. ¿Me pudieras para poder pagar la cuenta?

(17) EL2: Gabriel, penosamente te voy a pedir un favor. Mira, en este momento yo he pagado una cuenta y se me ha sobregirado la cuenta de ahorros. Son cien dólares, a mí me pagan el viernes. Por favor, si está a 


\section{Carolina Gutiérrez-Rivas}

tu alcance, ¿me pudieras prestar cien dólares hasta el viernes para que esa cuenta no me sobregire?

En la tercera generación se observó preferencia por el pronombre "tú", como en (18), o por la omisión del pronombre y uso de las formas gramaticales correspondientes a la segunda persona (ejemplos (19) y (20)). En estos últimos dos ejemplos se llega a la atenuación por medio de las explicaciones y las promesas

(18) EL3: Carlos, mira, necesito dinero porque... tengo ¿una deuda? Una deuda y necesito dinero. ¿Tú puedes darme cincuenta pesos?

(19) LM3: ¡Lizzie, Lizzie, por favor! Tengo un problema, que tengo que pagar unas deudas y no tengo dinero, y yo sé que su, tú, tú eres una buena amiga mía y... tú sabes que yo te lo pago en, la semana que viene o cuando quieras, pero por favor si me lo puedes prestar te lo agradezco mucho.

(20) AC3: Tú sabes que yo nunca te pidiera dinero, y solamente una situación que no tengo otra opción, si me lo pudieras prestar y yo te lo devuelvo cuando pueda.

Sin embargo, se observó un caso, el (21), en el que, a pesar estar tratando con un interlocutor de igual rango, la hablante empleó el pronombre de deferencia "Ud.", alternado con formas gramaticales de segunda y tercera persona. En este ejemplo, la hablante no sólo intenta salvaguardar su propia imagen, sino que da muestras de consideración hacia su interlocutora al ofrecer explicaciones y concretar una fecha para devolver el préstamo, puesto que comprende el peso que impone su petición sobre la oyente

(21) DZ3: Kika, otra vez, me da pena, pero mira, que tengo esto que tengo que pagar... la deuda, lo que sea, si me lo puede prestar, y mira, me van a pagar esta semana y vamos a ver si con tiempo te pago, entre dos meses o lo que sea, si Ud. lo tiene ahí..., pero si lo tiene sin usar, if you have it at hand, si me lo puede prestar para esto y yo te pago entre lo que sea el tiempo.

En general, en sociedades más solidarias, como la cubana, se esperaría encontrar el pronombre formal con personas con quien se tiene una relación vertical (+/-poder), pero no en situaciones donde la distancia y el poder son iguales. Blas Arroyo ha hecho notar que el corolario del poder en su aplicación al sistema pronominal es la elección de formas diferentes según la jerarquía relativa del interlocutor: "el superior dirige T al inferior mientras recibe V de éste" (1994:24). Asimismo, el autor señala que variables sociales como las de relaciones de parentesco y las afinidades de grupo (sexo, edad, nacionalidad, aficiones, afiliaciones) promueven el trato de solidaridad. Lo que se observa en este grupo de bilingües es que, por poseer una dimensión psicosocial diferente, su uso de los pronombres de tratamiento en español responde básicamente al contexto particular de habla (muy diferente al monolingüe) en el que éstos interactúan. Por la falta de 
lo que Blas Arroyo llama "experiencia intuitiva previa" (1994:28), los bilingües usan el pronombre de deferencia para atenuar la petición ante un interlocutor con el cual no tienen distancia social, pero frente a quien, dado el peso de la petición, sienten un enorme riesgo a perder la imagen. Hay que recordar que Miami, como una de las urbes más cosmopolitas del mundo, es una ciudad cuya economía ha florecido gracias a las industrias turísticas, televisivas y disqueras, donde se da importancia a las tiendas, la moda, las compras, a las mansiones de lujo de ricos y famosos y donde, por ende, el dinero y las apariencias ejercen mucho peso, culturalmente hablando. Por lo tanto, no es de extrañar que los bilingües que se han criado en ella sientan la preocupación de proteger la apariencia y salvaguardar la imagen frente a los demás, incluso ante personas que les son cercanas, cuando se trata de asuntos como el financiero.

\section{INFORME SOBRE EL PROTOCOLO DE AUTOEVALUACIÓN ORAL}

Al finalizar la dramatización de las situaciones específicas, se realizó, con cada hablante, un protocolo de autoevaluación oral, en el que se les preguntó a los participantes si al dirigirse a personas con quienes tuvieran poca confianza lo hacía usando el pronombre "tú" o "Ud.". Se usó sólo la variable de más distancia social en la pregunta asumiendo que con menos distancia el uso del "tú" sería invariable, dado lo que se ha discutido anteriormente sobre la tendencia hacia la cortesía de solidaridad de la sociedad cubana, apoyado en autores como Lipski (1996) y Ruzicková (1998, 2006, 2007).

Los resultados obtenidos ayudaron a enriquecer el análisis con una perspectiva sobre lo que opinan estos hablantes de su propio uso de los pronombres, y fueron los siguientes: $60 \%$ de los encuestados afirmó que, al tratar con personas con quienes tienen poca confianza, usan siempre el pronombre "Ud.", $30 \%$ afirmó usar el pronombre "tú", y 10\% contestó que no sabe. Las cifras sugieren que estos bilingües se perciben a sí mismos como más formales, ya que creen usar más el pronombre de deferencia, "Ud.", que el pronombre de solidaridad, "tú". Sin embargo, al cuantificar el número de actos de habla en los que aparece el "Ud." y en los que aparece el "tú", se observó que la tendencia es hacia el uso de este último. Posteriormente, al comparar estas cifras con las de los enunciados que presentan omisión de pronombre, pero en los que A) predominan las formas verbales de segunda persona, o B) predominan las formas verbales de tercera persona, se concluyó que, en general, la tendencia de este grupo de hablantes es a mostrar solidaridad a través del pronombre "tú", o las formas verbales que concuerdan con este pronombre. A continuación se muestra, en la Tabla 1, la contabilización de los enunciados en los que se produjo cada pronombre, más la omisión de los mismos con las formas verbales de la segunda o la tercera persona. Se entiende por enunciado todo el discurso que contiene, comprende y rodea al acto de habla. 
TABLA 1

Cuantificación del uso u omisión de los pronombres "tú" y "Ud." por parte de los bilingües cubanoamericanos de segunda y tercera generación

\begin{tabular}{|l|l|l|l|}
\hline & $\begin{array}{l}\text { Segunda Generación } \\
n(\%)\end{array}$ & $\begin{array}{l}\text { Tercera Generación } \\
n(\%)\end{array}$ & $\begin{array}{l}\text { Total } \\
n(\%)\end{array}$ \\
\hline Enunciados & $30(50)$ & $30(50)$ & $60 \quad(100)$ \\
\hline Uso explícito de "tú" & $3(5)$ & $8(13)$ & $33 \quad(55,3)$ \\
\hline $\begin{array}{l}\text { Omisión de "tú" } \\
\text { (Uso de las formas } \\
\text { de solidaridad) }\end{array}$ & $14(23,3)$ & $19(32)$ & $7 \quad(11,6)$ \\
\hline $\begin{array}{l}\text { Uso explícito } \\
\text { de "Ud." }\end{array}$ & $5(8,3)$ & $2(3,3)$ & $9 \quad(14,6)$ \\
\hline $\begin{array}{l}\text { Omisión de "Ud." } \\
\text { (Uso de las formas } \\
\text { deferenciales) }\end{array}$ & $8(13)$ & $1(1,6)$ & \\
\hline
\end{tabular}

Como se observa en la Tabla 1, los porcentajes reflejan que, en el continuo generacional, la tercera generación presenta las frecuencias más altas de uso del pronombre "tú", así como la omisión del mismo, pero con un elevado índice de formas gramaticales correspondientes a la segunda persona. La segunda generación, sin embargo, presenta poca diferencia entre el uso de los pronombres "tú" y "Ud.", aunque también muestra cierta tendencia a usar más las formas de solidaridad, es decir, las que corresponden a la segunda persona.

De igual modo, al comparar lo obtenido en el conteo con lo informado por los hablantes en el protocolo de autoevaluación oral, se observó discrepancia entre la percepción de estos bilingües sobre su propio uso de los pronombres con la producción real. Como se mencionó, un $60 \%$ de los entrevistados considera que usa siempre el pronombre "Ud." con personas con las que la distancia social es mayor, pero el análisis cuantitativo reveló que estos bilingües utilizan el pronombre "tú" y las formas gramaticales correspondientes a la segunda persona en un $73 \%$ de las veces. Un análisis tabular bivariado con Chi cuadrado, con un nivel de significancia predeterminado en 0,05 reveló que el valor de $\mathrm{P}$ no es significativo entre las dos generaciones $(\mathrm{P}=0,20)$.

\section{RESUMEN Y REFLEXIÓN FINAL}

Hemos descrito la variación del uso de los pronombres de deferencia y solidaridad, "Ud." y "tú," para efectos de empatía y distanciamiento en los actos de habla, por parte de un grupo de veinte bilingües cubanoamericanos residenciados en la ciudad de Miami, Florida. En un esfuerzo por ilustrar una faceta de la situación pragmática actual de esta comunidad, se incluyó una cantidad sustancial de enunciados que mostraban que la inserción en la petición del pronombre deferencial 
"Ud." y, en algunos casos, las formas verbales de tercera persona, sirven tanto de atenuadores como de intensificadores y tienen una intención específica: ayudar al hablante a establecer su estatus frente el oyente. En otras palabras, en el discurso de los bilingües, este pronombre cumple con una doble función pragmática: la primera es la de ensalzar al oyente y expresarle empatía y consideración, sin importar si las relaciones son de tipo simétrico o asimétrico. La inserción del pronombre formal en puntos específicos del discurso se debe más a la necesidad pragmática y la intención de fijar una postura de respeto y consideración frente al oyente (recuérdense ejemplos como el (2), el (11) y el (21)); o la de marcar distancia con el interlocutor cuando se está en una posición de autoridad (como por ejemplo en (9) y en (10)). En cuanto al pronombre de solidaridad, "tú", y las formas verbales correspondientes a la segunda persona, se observó que los bilingües los usan con más libertad en los casos en los que la distancia no es importante, o bien porque el hablante tiene más poder, o bien porque ambos interlocutores tienen una relación no vertical. El uso del pronombre informal sigue teniendo la función de mostrar solidaridad y empatía (como se vio en ejemplos como el (12), (15) y (18), entre otros).

Igualmente, se produjeron casos que, en español monolingüe, serían considerados como "polimorfismo", y que consisten en el uso de ambos pronombres con un mismo sujeto. Sin embargo, la alternancia de ambos pronombres, así como de las distintas formas gramaticales de segunda y tercera persona, no se puede atribuir exclusivamente al polimorfismo observado en el habla monolingüe, debido a que el español de los bilingües se ve afectado por factores externos que poco interfieren con el habla monolingüe, tales como un contexto sociocultural con una lengua dominante distinta al español y la poca frecuencia de uso del segundo idioma. Al respecto, Blas Arroyo (2005) ha comentado que si bien los empleos de "tú" o "Ud." responden a maneras de actuar ritualizadas que han sido postuladas innumerables veces por la tradición gramatical como una dicotomía conceptual (lo solidario y familiar vs. lo distante y cortés), tales usos pueden diferir entre las diversas comunidades de habla, o incluso dentro de una misma comunidad de habla, con sociolectos diferentes. Lo observado en la presente investigación sustenta la noción de que lenguas como el español, cuyas gramáticas reflejan las diferencias pragmáticas y sociales de sus hablantes, son objeto de cambio lingüístico constante. Estos bilingües usaron explícitamente las formas de tratamiento dependiendo de su posición frente al interlocutor y su deseo de salvaguardar su imagen o de crear un nexo con éste, sin acatar necesariamente la norma de "tú" = (-deferencia/+solidaridad), "Ud." = (+deferencia/-solidaridad). Se infiere que una razón de peso para el uso alternado de los pronombres y las distintas formas gramaticales se debe en gran medida a que la socialización de los hablantes de segunda y tercera generación ha ocurrido en los Estados Unidos, donde han recibido toda la escolarización en inglés (lengua que además consiste de un solo pronombre de tratamiento para la 
segunda persona (“you”)), y donde predomina más el inglés que el español en contextos y dominios socialmente formales (la educación, el gobierno, la prensa).

Por último, también se concluye que la variable externa de la edad también es otro factor que puede estar contribuyendo al favorecimiento de la forma pronominal informal, "tú", sobre la formal, "Ud.". Como se recordará, los bilingües de tercera generación (de edades comprendidas entre los 18 y los 28 años de edad) tendieron a usar mucho más el pronombre de solidaridad, lo cual puede deberse a un cambio en marcha propio del español, que también se está observando en otras regiones del mundo hispano. Blas Arroyo (Tú y Usted) explica que sus datos: "confirman que el avance de la forma pronominal de solidaridad máxima (tú) se desarrolla principalmente a partir de los grupos de edad más jóvenes" (33). Más adelante, el autor afirma que este fenómeno "es una prueba de los cambios latentes que en torno a este fenómeno sociolinguístico se están produciendo en la sociedad española actual" (39).

Debido al auge que han cobrado últimamente los estudios sobre los actos de habla y cortesía dentro de la lingüística hispánica, se sugiere que para futuras investigaciones se indague más sobre el uso de los pronombres de tratamiento en otras comunidades de habla bilingües, así como también sobre otras diferencias pragmáticas que presentan los bilingües de origen hispano en los EE.UU.

Universidad Simón Bolívar (USB)*

Departamento de Lengua y Literatura

Edif. EGE, oficina 306-A. Edo. Miranda, Apartado 89000

Valle de Sartenejas, Caracas (Venezuela)

ltexts@gmail.com

\section{BIBLIOGRAFÍA}

Ardila, Alfredo. "Spanglish: an anglicized Spanish dialect", en Hispanic Journal of Behavioral Sciences 27-1, (2005):60-81.

Ardila, J.A.G. "Variables sociopragmáticas de contextualización y niveles de concreción de la cortesía en castellano e inglés", en Revista Electrónica del Departamento de Español y Estudios Internacionales, Instituto de Lenguas y Estudios Interculturales 3 (2003):1-21. Dinamarca: Aalborg University.

Blas Arroyo, José L. "Los grados de la cortesía verbal: reflexiones en torno a algunas estrategias y recursos lingüísticos en el español peninsular contemporáneo", en Revista Internacional de Lingüística Iberoamericana 3 (2005):25-31.

------ "Tú y Usted: dos pronombres de cortesía en el español actual. Datos de una comunidad peninsular", en Estudios de Lingüística 10 (1994):21-44.

Blum-Kulka, Shoshana; Juliane House; Gabriele Kasper. (Eds.). Cross-Cultural Pragmatics: Requests and Apologies. Norwood, NJ: Ablex, 1989.

Brown, Penelope; Steven Levinson. Politeness: Some Universals in Language Usage: Politeness. Cambridge University Press, 1987. 
Brown, Roger; Albert Gilman. "The Pronouns of Power and Solidarity”, en Language and Social Contex. Hamondsworth, P. Gilioli (Ed.). Middlessex: Penguin, 1977:252282.

Curcó, Carmen. "¿No me harías un favorcito? Reflexiones en torno a la expresión de la cortesía verbal en el español de México y el español peninsular", en $L a$ Pragmática Lingüística del Español: Recientes Desarrollos. H. Haverkate (Eds.). Amsterdam, Rodopi, 1998:129-171.

------ y Anna De Fina. "Modo imperativo, negación y diminutivos en la expresión de la cortesía en español: el contraste entre México y España", en Actos de Habla y Cortesía en Español. M.E. Placencia \& D. Bravo (Eds.). Muenchen: Lincom Europa, 2002:105-140.

Ervin-Tripp, Susan. "On sociolinguistic rules: alternation and co-occurrence", en Directions in Sociolinguistics, Gumperz, J. \& D. Hymes (Eds.). New York: Holt, Rinehart and Winston, 1972:213-250.

Félix-Brasdefer, J.César. "Validity in data collection methods in pragmatic research", en Theory, Practice and Acquisition. P. Kempchinsky, \& C.E. Piñeros. (Eds.). Somerville, MA: Cascadilla Press, 2003:239-257.

Gumperz, John; DELL, Hymes (Ed.). Directions in Sociolinguistics; the Ethnography of Communication. New York: Holt, Reinehart y Winston, 1972.

Hasbún, Leyla, y Mayra Solís. "Análisis de los usos asimétricos de las formas de tratamiento pronominal en una comunidad costarricense", en Revista de Filología y Lingüística 23 (1997):139-152.

Johnstone, Barbara. Discourse Análisis. Malden, MA: Blackwell, 2005.

Lavandera, Beatriz. Variación y significado. Buenos Aires: Hachette, 1984.

Lipski, John. El español de América. Madrid: Longman, 1996.

Lynch, Andrew. "Exploring turn at talk in Spanish: native and nonnative speaker interactions", en Spanish Applied Linguistics 2. 1998:199-228.

Murillo, Mary Edith. "El polimorfismo en los pronombres de tratamiento del habla payanesa", en Actas del Congreso Internacional "Pronombres de segunda persona y formas de tratamiento en las lenguas de Europa”. París: Instituto Cervantes, 2003.

Penny, Ralph. A History of the Spanish Language. Cambridge: Cambridge University Press, 2002.

Rey, Alberto. "Social correlates of the voseo of Managua, Nicaragua: Family and neighborhood domains", en Hispanic Journal, 17 (1996):113-27.

Ruzicková, Elena. Face, Face Threatening Acts and Politeness in Cuban Spanish. (Unpublished doctoral dissertation). University of Pittsburgh, 1998.

"Strong and mild requestive hints and positive-face redress in Cuban Spanish", en The Journal of Pragmatics 39 (2006):1170-1202.

------ "Customer requests in Cuban Spanish: Realization Patterns and Politeness Strategies in Service Encounters", en Research on Politeness in the SpanishSpeaking World, M.E. Placencia \& C. García (Eds.). Mahwah, N.J.: Erlbaum, 2007:213-241.

Said-Mohand, Aixa. "Estudio sociolingüístico de los marcadores como, entonces y tú sabes en el habla de bilingües estadounidenses". (Unpublished doctoral dissertation). University of Florida, 2006. 


\section{Carolina Gutiérrez-Rivas}

Searle, John. "Indirect Speech Acts", en Syntax and Semantics. Vol 3: Speech Acts. P. Cole y J. Morgan (Eds.). New York: Academic Press, 1975:59-82.

Scollon, Ron; SUZANNE Scollon. Intercultural Communication: A Discourse Approach. Malden, MA: Blackwell, 2001.

------ "Face in interethnic communication", en Language and Communication. Jack C. Richards and Richard W. Schmidt (Eds.). New Yok: Longman, 1983:156-190.

Silva-Corvalán, Carmen. Sociolingüística y pragmática del español. Washington D.C.: Georgetown University Press, 2001.

Stewart, Miranda. "Pragmatic weight' and face: pronominal presence and the case of Spanish second person singular subject tú", en Journal of Pragmatics 35. 2003:191-206.

Turell, M. Teresa. "La auto-referencia pronominal en el ámbito laboral juvenil", en Comunicación y lenguaje juvenil. Félix Rodríguez Gonzáles (Ed.). Madrid: Fundamentos, 1989:293-304.

Uber, Diane. "The dual function of usted: Forms of address in Bogotá, Colombia", en Hispania 68. 1985:388-92.

Valdés, Guadalupe. "Codeswitching as a Deliberate Verbal Strategy: A Microanalysis of Direct and Indirect Requests Among Bilingual Chicano Speakers", en Latino Language and Communicative Behavior. R.P. Durán (Ed.). Norwood, NJ: Ablex, 1981:95-107.

Zentella, Ana Celia. Growing Up Bilingual: Puerto Rican Children in New York. Malden, MA: Blackwell, 1997. 